\title{
Wnt signaling and colon carcinogenesis: Beyond APC
}

\author{
Rani Najdi*, Randall F. Holcombe ${ }^{1}$, Marian L. Waterman \\ Department of Microbiology and Molecular Genetics, University of California, Irvine, ${ }^{1}$ Tisch Cancer Institute, Mt. Sinai School of Medicine, New York, NY \\ E-mail: rnajdi@uci.edu \\ *Corresponding author
}

Published: 17 March, 20II

Received: 25 January, 20II

Journal of Carcinogenesis 2011, 10:5

Accepted: 18 February, 2011

This article is available from: http://www.carcinogenesis.com/content/l0/l/5

(c) 2011 Najdi,

\begin{abstract}
Activation of the Wnt signaling pathway via mutation of the adenomatous polyposis coli gene (APC) is a critical event in the development of colon cancer. For colon carcinogenesis, however, constitutive signaling through the canonical Wnt pathway is not a singular event. Here we review how canonical Wnt signaling is modulated by intracellular LEF/TCF composition and location, the action of different Wnt ligands, and the secretion of Wnt inhibitory molecules. We also review the contributions of non-canonical Wnt signaling and other distinct pathways in the tumor micro environment that cross-talk to the canonical Wnt pathway and thereby influence colon cancer progression. These 'non-APC' aspects of Wnt signaling are considered in relation to the development of potential agents for the treatment of patients with colon cancer. Regulatory pathways that influence Wnt signaling highlight how it might be possible to design therapies that target a network of signals beyond that of APC and $\beta$-catenin.
\end{abstract}

Keywords: Adenomatous polyposis coli gene, colon carcinogenesis, Wnt signaling

\section{BACKGROUND}

Wnt ligands are a large family of highly conserved secreted proteins that are important for normal cell development. Wnts bind to receptors at the plasma membrane and initiate intracellular signaling cascades to control a wide variety of processes in embryonic development and adult homeostasis, including cell proliferation, cell polarity, and specification of cell fate. These effects are wide-ranging and powerful and they are also complex, there being multiple types of Wnt signals. Traditionally, Wnt signals have been classified into two types: canonical ( $\beta$-catenin-dependent) and noncanonical ( $\beta$-catenin-independent). This classification was

\begin{tabular}{|l|l|}
\hline \multicolumn{3}{|c|}{ Access this article online } \\
\hline Quick Response Code: & Website: \\
\hline & www.carcinogenesis.com \\
\cline { 2 - 2 } & \\
\hline
\end{tabular}

based on the biological activity of Wnt overexpression in Xenopus embryos, where canonical Wnts (such as Wnts 1 and 3a) induced the formation of a secondary axis and non-canonical Wnts did not (e.g., Wnts 4, 5a, and 11). In fact, non-canonical Wnts directly suppressed the ability of canonical Wnts to induce a secondary axis. This initial characterization was functional and straight forward and it created a simple framework to classify ligands. Since then, however, the picture has become more complex. Wnt action is context dependent, there are multiple intracellular cascades that can be triggered, and some of these cascades are composed of a blend of canonical and non-canonical components. A review by van Amerongen and Nusse offers highlights of the complexities in Wnt signal transduction and discusses the limitations that come from simple classification into two linear pathways. ${ }^{[1]}$ In this review we link some of these signaling complexities to a consideration of therapeutic strategies for colon cancer.

Canonical Wnts signal through the transcriptional coactivator $\beta$-catenin. In the absence of such ligands, 
cytoplasmic $\beta$-catenin is captured by a destruction complex composed of adenomatous polyposis coli (APC), glycogen synthase kinase 3- $\beta$ (GSK-3 $\beta$ ), Axin, and other components. Captured $\beta$-catenin is phosphorylated, ubiquitinated, and degraded, preventing its translocation to the nucleus and interaction with members of the LEF/TCF transcription factor family (LEF-1/LEF1, TCF-1/TCF7, TCF-3/TCF7L1, and TCF-4/TCF7L2). ${ }^{[2,3]}$ When canonical Wnt ligands are present, they bind to a receptor complex consisting of the seven-pass transmembrane protein Frizzled $(\mathrm{Fz})$ and the single-pass LRP5/6 receptor (lipoprotein-related protein 5 or 6). Binding of these receptors recruits the scaffolding protein Dishevelled (Dvl), which leads to LRP5/6 phosphorylation and the recruitment of Axin and GSK-3 $\beta$ away from the destruction complex. Disruption of the destruction complex releases $\beta$-catenin and allows it to accumulate in the nucleus along with LEF/TCFs. As nuclear concentrations increase, $\mathrm{LEF} / \mathrm{TCF}$ recruit $\beta$-catenin to target genes and nucleate its associations with co-regulators Pygopus, BCL9/Legless, and transcription-activating complexes such as the CDK8 module of Mediator and TRRAP. ${ }^{[4-10]}$ Therefore, the key characteristics of canonical signaling are the requirement for the LRP5/6 co-receptor to enable $\beta$-catenin accumulation and the involvement of LEF/TCF transcription factors.

Wnts that signal non-canonically eschew LRP co-receptors and $\beta$-catenin stabilization to activate intracellular kinases and regulate distinct $\beta$-catenin-independent pathways. These include the planar cell polarity (PCP) pathway and the Wnt/calcium pathway. First identified in Drosophila, the PCP pathway, which is mediated by Fz and Dvl, activates c-Jun-N-terminal kinase (JNK) and Rho-associated kinase (Rho-kinase) to control the orientation of hairs, bristles, and ommatidia in flies. Non-canonical Wnts binding to $\mathrm{Fz}$ can also stimulate an increase in intracellular $\mathrm{Ca}^{2+}$ levels, thereby activating calcium-sensitive proteins such as $\mathrm{Ca}^{2+}$ / calmodulin-dependent protein kinase II (CaMKII) and protein kinase $\mathrm{C}(\mathrm{PKC})$. Importantly, the Wnt/calcium pathway has been shown to antagonize $\beta$-catenin-dependent signaling and stimulate cell migration. ${ }^{[11,12]}$ Even though these pathways are very different from canonical signaling, it has been suggested that the classification of Wnt ligands as either canonical or non-canonical is too simple. Recent reports show that Wnts can signal through both types of pathways, with opposing outcomes; it all depends on the receptor context. ${ }^{[13]}$ The best studied example is Wnt5a, a ligand family member traditionally considered to activate non-canonical signaling. Wnt5a inhibits $\beta$-catenin-dependent activity when its signal is mediated by the orphan tyrosine kinase Ror2. ${ }^{[14]}$ But when Wnt5a signals through the co-receptors Fz4 and LRP5, it activates $\beta$-catenin-dependent signaling. More recently, Wnt5a has been shown to heterodimerize with another Wnt to direct $\beta$-catenin outcomes. Wnt5a heterodimerizes with the non-canonical Wnt11 ligand to upregulate canonical Wnt signaling in Xenopus embryos. ${ }^{[15]}$ If this important discovery applies to all Wnt ligands, that is, if the entire family can engage in heterodimer formation, then signaling potential and outcomes of any one Wnt are even more influenced by the context of other Wnt ligands and receptors in cells.

\section{ROLE OF WNT SIGNALING IN DEVELOPMENT, DIFFERENTIATION,AND CARCINOGENESIS}

Wnt signaling plays a critical role in embryonic development. Wnts direct programs of proliferation, stem cell self-renewal, cell fate decisions, cell polarity, and convergent extension behaviors of migrating cells. ${ }^{[3-4,11,16]}$ Each of these Wntdirected outcomes are critical for proper development of the intestine. ${ }^{[17]}$ For example, the now classic knockout experiments by the Clevers laboratory showed that loss of the TCF7L2 locus (TCF-4) depletes stem cell compartments in the intestines of mouse embryos because cells are unable to proliferate and repopulate crypts. ${ }^{[18]}$ Stem cell self-renewal also relies on Wnt signaling. This is true in the Drosophila gut and, recently, it has been shown to be true in the mammalian gut. ${ }^{[19,20]}$ The Wnt target gene, LGR5, has been identified as the multipotent stem cell marker in crypts. Other Wnt target genes such as ASCL2, SOX9, Paneth cell defensins, and others control additional steps of differentiation from the stem cell through to the terminally differentiated phenotype. ${ }^{[17,21-23]}$

Due to its key role in regulating early cell fate decisions and adult cell homeostasis, Wnt signaling has been extensively investigated for its involvement in cancer. ${ }^{[16]}$ Many components of the $\beta$-catenin-dependent pathway are often differentially regulated between normal tissue and its cancerous counterpart. In particular, melanoma, hepatocellular carcinoma (HCC), prostate, colon, thyroid, and ovarian cancers, as well as certain subsets of breast cancers, harbor $\beta$-catenin-stabilizing mutations. ${ }^{[24-26]}$ Such mutations result in high levels of $\beta$-catenin which, in turn, translate into constitutively active Wnt signaling. ${ }^{[26-28]}$ While the regulation of $\beta$-catenin appears to be one of the most significant events linking Wnt signaling to cancer, modulation of other pathway components, both upstream and downstream of $\beta$-catenin, has also been shown to play a role. However, the most striking link between Wnt signaling and cancer has been the discoveries of genetic mutations in midstream signaling components (APC, $\beta$-catenin) which cause a constitutive activation of canonical signaling.

\section{Role of Wnt signaling in colon carcinonesis}

Activation of the Wnt pathway has been linked to colon 
cancer since the recognition that abnormalities of chromosome $5 q$ were early events in the carcinogenic process for sporadic and hereditary (familial adenomatous polyposis, FAP) tumors, and the discovery that the FAP locus resides at this chromosomal location. ${ }^{[29-31]}$ Encoded at $5 \mathrm{q}$ is the $A P C$ gene, the protein product of which is a key component of the $\beta$-catenin destruction complex. ${ }^{[27,30,32-34]}$ About $90 \%$ of sporadic colon cancers harbor activating mutations within the Wnt pathway; most of these mutations destroy APC function. ${ }^{[35]}$ Truncating mutations in APC prevent effective phosphorylation of $\beta$-catenin, resulting in its accumulation. Ultimately, $\beta$-catenin translocates to the nucleus, driving LEF/TCF-mediated gene transcription. ${ }^{[36]}$ The same outcome can arise through mutations in $\beta$-catenin and Axin2, though these are significantly less frequent than mutations in $A P C .{ }^{[28,37]}$

Activation of the Wnt pathway by these mechanisms does not, by itself, cause cancer, though it is important in initiating the carcinogenic process. Inherited mutations in APC, as in FAP, lead to the development of noninvasive colonic adenomas (polyps), often thousands of them in an individual patient. Presumably, this is caused directly by the overexpression of growth-promoting genes driven by $\beta$-catenin-LEF/TCFs through canonical Wnt signaling. Mouse models of FAP, such as the $\mathrm{Apc}^{\mathrm{min} /+}$ mouse, are characterized by innumerable intestinal (in this case, primarily small bowel) tumors, but these are typically noninvasive and most analogous to human colonic adenomas. ${ }^{[38]}$ Similarly, somatic mutations in $A P C$ are an early event in sporadic adenoma formation. While Wnt pathway activation is clearly a driving force in the development of adenomas, activation of additional signaling pathways, such as those mediated through the proto-oncogene $K$-ras, are required for optimal nuclear localization of $\beta$-catenin to the nucleus and activation of the carcinoma program. ${ }^{[39]}$ Additional mutations (TGFBRII, $S M A D 4$, and TP53) may be necessary before frank carcinoma develops. ${ }^{[29]}$ Because of the central role of $A P C / \beta$-catenin in controlling mucosal proliferation and in the development of precancerous adenomas, almost all of the focus on the Wnt pathway in colon cancer has been on the linear path of canonical signaling. It is only recently that there has been recognition of the potential importance of non-mutational modulation of the Wnt signal (i.e., via cell surface receptor and ligand interactions) and of non-canonical components of the pathway. This review highlights two types of modulators: LEF/TCFs in the nucleus and extracellular signals from the tumor microenvironment.

\section{Modulation of Wnt signaling in colon cancer LEF/TCFs}

$\mathrm{LEF} / \mathrm{TCF}$ transcription factors are expressed in various tissues

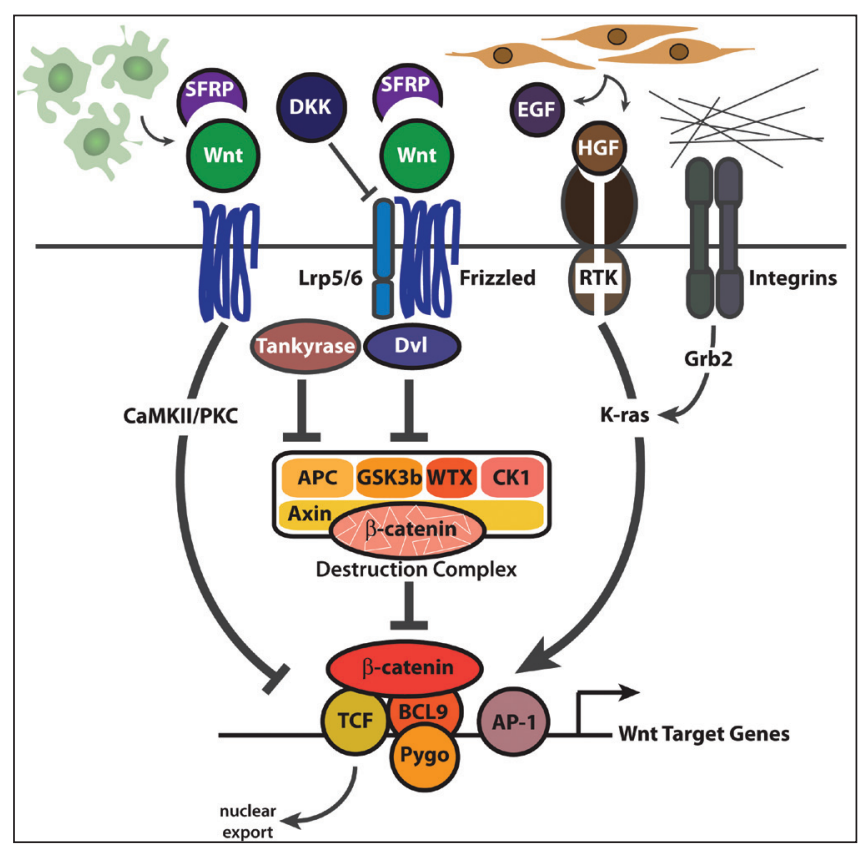

Figure 1: Pathways that modulate canonical Wnt signaling. Canonical Wnt signaling requires Frizzled (Fz) receptors and a LRP5/6 coreceptor. This signal induces stabilization of $\beta$-catenin through Dishevelled (Dvl)-mediated inhibition of the destruction complex. Stabilized $\beta$-cateninaccumulates in the nucleus where TCFs recruits it and associated co-regulators BCL9 and Pygopus (Pygo) to Wnt target genes for regulation. Tankyrase is an enzyme recently discovered to inactivate the destruction complex through ADP PARsylation of Axin. Secreted inhibitors such as DKK-1, DKK-2, and DKK-3 prevent canonical signaling through negative actions on LRP5/6. Secreted inhibitors such as the SFRPs inhibit all types of Wnt signaling by direct binding to Wnt ligands (WIF and others not shown). Wnt ligands are present in the tumor microenvironment through production by cancer cells and infiltrating lymphocytes and macrophages (green cells), which release Wnt 5a. Non-canonical types of Wnt signaling do not involve LRP5/6 co-receptors, and they trigger multiple kinase cascades, including those that involve calcium/calmodulin-dependent kinase II (CaMKII), protein kinase C (PKC), and others (c-Jun-N-terminal kinase and the planar cell polarity pathway not shown). Activation of these signals can inhibit the actions of LEF/TCFs, including the nuclear export of TCF-1, even in colon cancer cells where the destruction complex is nonfunctional and high levels of $\beta$-catenin are constitutively available. Other signals released in the tumor microenvironment (i.e.,stromal fibroblasts, brown cells) activate pathways that enhance Wnt target gene regulation. Pathways relevant to colon cancer include signaling through receptor tyrosine kinases (RTK) for epidermal growth factor (EGF) and hepatocyte growth factor/scatter factor (HGF), or through integrin receptors to growth factor receptor-bound protein-2 (Grb2). RTK and integrin signaling activates K-RAS, a GTPase often detected as a mutation-activated oncogene in colon tumors and a pathway that stimulates the formation of the transcription factor activator protein-1 (AP-1).

during embryonic development, where they mediate proper Wnt signaling. ${ }^{[40]}$ After birth, they continue to mediate Wnt signaling, especially in tissues that derive from stem cell populations. LEF/TCFs also play important roles in colon cancer and in this regard the collective pattern of expression is important to consider because it changes in ways that maximize canonical Wnt signaling in cancer. Canonical signaling depends on the recruitment of $\beta$-catenin to target 
genes through a $\beta$-catenin-binding domain at the $\mathrm{N}$-terminus of LEF/TCFs. The HMG box, a sequence-specific DNA binding/bending domain near the C-terminus of LEF/TCFs, allows the $\beta$-catenin-LEF/TCF complex to recognize Wnt response elements in target genes. Both of these functional domains are highly conserved and present in all LEF/TCFs, leading one to expect that LEF/TCF proteins are functionally redundant. However, this is not the case, because different $\mathrm{LEF} / \mathrm{TCF}$ loci can produce differently acting protein isoforms through the use of alternative promoters and/or alternative splicing. ${ }^{[2,40]}$ For example, an alternative splicing event in the TCF7 (produces TCF-1) and TCF7L2 (produces TCF-4) genes leads to the inclusion of a carboxy-terminal domain called the E-tail. This tail contains a highly conserved second DNA-binding domain called the C-clamp. ${ }^{[41,42]}$ The C-Clamp has sequence selectivity and enables access to a set of Wnt target genes that are important for cell proliferation in colon cancer cells. ${ }^{[41]}$ In addition to differences in DNA binding, alternative promoters in TCF7 and LEF1 produce dominant negative forms that are missing the $\beta$-cateninbinding domain (dnTCF-1 and dnLEF-1). These truncated isoforms act as dominant negative versions and negatively regulate Wnt signaling. ${ }^{[43,44]}$

The expression pattern of LEF/TCF loci and isoforms is different in normal human colon as compared to colon cancer. In the normal colon, family members TCF-1 and TCF-4 are expressed and LEF-1 and TCF-3 loci are silent. ${ }^{[43,45,46]}$ The TCF7L2 locus produces a full-length form of TCF-4 that contains the C-clamp auxiliary DNA-binding domain (TCF-4E), but the predominant isoform produced from the TCF7 locus is a dominant negative isoform of TCF-1, also with a C-clamp domain (dnTCF-1E). ${ }^{[4]}$ That the TCF7L2 gene produces a Wnt-promoting form of TCF-4 that is important for proliferation and stem cell self-renewal is borne out in the Clevers' knockout mouse model, where loss of TCF-4 depletes stem cells and eliminates cell proliferation in the intestine. ${ }^{[18]}$ That TCF-1 might be functioning as a homeostatic counterbalance to TCF-4 through its expression as a dnTCF-1E isoform is also borne out in mouse knockout studies, where loss of TCF-1 leads to adenoma formation in this tissue. ${ }^{[46]}$

The situation is quite different in colon cancer. While TCF-4 continues to be expressed as a full-length form with two DNA-binding domains, TCF-1 expression changes dramatically to a full-length Wnt-promoting isoform (TCF1B). ${ }^{[47]}$ Also, because LEF1 is a Wnt target gene, it is activated by the developing oncogenic Wnt signal, and full-length $\beta$-catenin-binding forms of LEF-1 are produced. A dnLEF-1 is not produced because its promoter is actively silenced through repressor action. ${ }^{[48,49]}$ Collectively, then, only full- length Wnt-promoting forms of LEF/TCFs are produced in cancer cells, a pattern that emerges for maximum $\beta$-catenin interaction and oncogenic Wnt signaling. ${ }^{[43,50]}$ Therapeutic strategies that restore normal levels and patterns of LEF/ TCF expression or those that counter their recruitment of $\beta$-catenin and its co-activators Pygopus, BCL9, or CDK8 could bypass the effects of the loss of the destruction complex and the stabilization of $\beta$-catenin.

\section{Wnt ligands and Wnt inhibitors in the tumor microenvironment} While loss of heterozygosity (LOH) at the APC locus or stabilizing mutations in $\beta$-catenin create a constitutive canonical Wnt signal, extracellular signals from the tumor microenvironment can influence oncogenic actions of the pathway, either by enhancing or repressing actions. Notably, there are changes in expression of Wnt ligands and secreted inhibitors that hint at the signaling potential of upstream components beyond the role of APC and $\beta$-catenin, an idea first noted in a study of autocrine Wnt signaling in cancer cells. ${ }^{[51]}$ For example, Wnt 2 and Wnt5a expression is elevated in colon cancer compared to normal colon and during the progression from adenoma to carcinoma. ${ }^{[52-54]}$ In contrast, the expression of other Wnts, including Wnts 2b, 4, 7b, and $10 \mathrm{~b}$, does not change, as they remain strongly expressed in both normal colon and colon cancer. ${ }^{[55]}$ In addition to Wnts, several $\mathrm{Fz}$ receptors $(\mathrm{Fz}-1$ and $\mathrm{Fz}-2)$ are upregulated in poorly differentiated tumors, and expression of the scaffolding protein Dvl1 is increased in IBD (inflammatory bowel disease)-related colon cancer. ${ }^{[52,56]}$ The differential expression of upstream Wnt components is not exclusive to Wnt ligands. Genes encoding secreted soluble inhibitors of Wnt signaling such as DKK-1, SFRPs (secreted Fz-related protein), and WIF-1 (Wnt inhibitory factor) are hypermethylated and therefore silenced in colon cancer. Reintroduction of SFRP and DKK-1 into colon cancer cells causes a loss of cancer phenotypes, such as tumor growth and colony formation in soft agar, and this is true even in colon cancer cells where the $A P C$ locus has suffered LOH and where oncogenic Wnt signaling is presumably constitutive. ${ }^{[55,57-59]}$ These findings hint that colon cancers with a mutated pathway and stabilized $\beta$-catenin might still derive growth advantages from autocrine/paracrine Wnt signaling at the Fz-receptor level.

Even though colon cancers might progress by altering expression of Wnt ligands and secreted inhibitors to maximize oncogenic Wnt signaling, other extracellular Wnt signals can arise that inhibit the pathway. Interestingly, such signals are linked to the actions of the non-canonical class of Wnt ligands. Much of what is known about inhibitory Wnt signals comes from studies using Wnt5a as the extracellular ligand and, notably, several studies of colon cancer report significant changes in Wnt5a expression. One study of Wnt5a 
in Dukes' B-stage cancer found its expression decreased in $50 \%$ of the tumors, but either normal or increased in the other half. ${ }^{[60]}$ Other comparative studies observed more consistent increases in Wnt5a expression. ${ }^{[33,56]}$ Differences in the reports are likely due to differences in methods used to detect Wnt5a; the first study examined protein and the second set of studies used methods to detect mRNA. It is possible that Wnt5a translation is regulated and mRNA and protein patterns are not always congruent. Nevertheless, Wnt5a expression shows upregulation in a significant cohort of tumors and this expression has been observed in both the epithelial and stromal compartment, which includes infiltrating macrophages. This is important because there is compelling evidence that Wnt5a can circumvent the constitutive oncogenic signaling in cells with defective, mutated APC. For example, $\beta$-catenin-dependent Wnt signaling in APCnegative colon cancer cells can be inhibited through the combined actions of Wnt $5 \mathrm{a} / \mathrm{calcium}$ signaling and ROR $\alpha$, a nuclear hormone receptor. ${ }^{[61]}$ Likewise, Macleod et al. report that calcium-induced secretion of Wnt5a causes an autocrine inhibition of $\beta$-catenin signaling in APC-defective colon cancer cells. This signal requires the ROR2 receptor for Wnt5a. ${ }^{[62]}$ Other groups find that Wnt5a treatment of APC-defective colon cancer lines reduces cancer behaviors such as cell migration and growth in soft agar (although the molecular basis for these effects was not explored). ${ }^{[6,63]}$

There is another type of inhibitory Wnt signal that develops in colon cancer. This signal reduces $\beta$-catenin-dependent signaling by triggering the nuclear export of TCF-1 and, in doing so, reduces the concentration of LEF/TCFs in the nucleus. ${ }^{[4]}$ This activity was discovered in primary human colon tumors where TCF-1 staining experiments showed dramatic shifts in localization to the cytoplasm. ${ }^{[4]}$ TCF-1 export is activated by autocrine, paracrine actions of Wnts and these actions can be inhibited by DKK-1 and SFRPs. DKK-1 sensitivity implicates $\beta$-catenin and a canonicaltype signal since this inhibitor works by blocking LRP5/6 action. However, the calcium-activated CaMKII/TAK1/ NLK kinase cascade is also involved, and this pathway is activated by Wnt5a and other non-canonical-type ligands. ${ }^{[64,65]}$ The requirement for both canonical and non-canonical components attests to the complexity of Wnt signaling and the cross-talk between its different arms. The Wnt/CaMKII signal antagonizes $\beta$-catenin-dependent canonical signaling in APC-defective colon cancer cells because the form of TCF-1 exported from the nuclei is a full-length TCF-1 with oncogenic potential. A Wnt5a/CaMKII signal can also negatively affect the DNA-binding activities of LEF-1 and TCF-4 in 293 cells. $^{[47]}$ Whether this specific action occurs in colon cancer is unknown, but LEF-1 and TCF-4 do not export and their expression levels do not change. ${ }^{[47]}$
Therefore, at a minimum, even though LEF-1, TCF-4, and $\beta$-catenin remain in the nucleus, TCF-1 export reduces the overall concentration of LEF/TCFs enough to affect canonical signaling. These data imply that LEF/TCF activities can be limiting for canonical signaling in colon cancer.

Are the actions of Wnt5a and calcium/CaMKII signals relevant to colon cancer? As mentioned above, Wnt5a expression can be elevated in colon cancer either through expression in the transformed epithelial cell compartment or through expression in stromal and inflammatory compartments such as infiltrating macrophages. ${ }^{[52,53,60]}$ Sporadic colon cancer is not thought to have an overriding inflammatory component, but inflammation can occur and, interestingly, an inflammatory signature correlates with a good prognosis. ${ }^{[66-69]} \mathrm{A}$ direct correlation between Wnt5a expression and prognosis is a more complicated issue, especially when all types of cancer are considered together. However, in the case of sporadic-type colon cancer, Wnt5a expression correlates with a better prognosis. ${ }^{[60,70]}$ If Wnt5a is truly a positive prognostic indicator, then the various Wnt5atype signals summarized here might be the main reason for better outcome, as they can bypass APC and repress oncogenic Wnt signaling.

\section{Cross-talking signals in the tumor microenvironment}

In contrast to Wnts that oppose oncogenic Wnt signaling, there are important examples of extracellular growth factorsand cross-talk interactions that enhance $\beta$-catenin actions. For example, many sporadic colon cancers contain activating mutations in the GTPase K-RAS (40\%). ${ }^{[71,72]}$ EGF (epidermal growth factor) and VEGF (vascular endothelial growth factor) signaling activates Rac/K-RAS pathways, which enhance canonical Wnt signaling by increasing the residence time and concentration of $\beta$-catenin in the nucleus. ${ }^{[39,73]}$ Adenomas from mouse models of intestinal cancer have increased levels of EGF receptor activity in the tumors. ${ }^{[74,75]}$ Moreover, inhibition of EGFR signaling in humans via blocking antibodies has proved to be an effective therapeutic intervention for patients with wildtype K-RAS. ${ }^{[76]}$ Also important to consider are the effects of HGF (hepatocyte growth factor/scatter factor), a factor recently shown to promote stable $\beta$-catenin accumulation in nuclei. ${ }^{[77]}$ HGF signals through the c-Met receptor and, although the signal transduction pathway is complex, there is a strong Ras component. HGF greatly enhances $\beta$-catenin signaling in experimental models of human colon cancer stem cells. ${ }^{[77]}$ Indeed, disruption of HGF cross-talk might have real potential intherapy since Met inhibitor treatment of mice injected with gastric carcinoma cells induces regression of metastases. ${ }^{[78]}$ Thus, there appears to be a strong synergy between K-RAS-dependent signals and oncogenic Wnt 
signals. Finally, signals from cell surface integrin-extracellular matrix interaction sengage non-canonical signaling to Rac/ JNK, which in turn triggers the formation of the AP-1 transcription factor. ${ }^{[79]}$ AP-1 action can synergize with Wnt signals to influence the activation of a subset of target genes. ${ }^{[80]}$ The interesting connection to Wnt target genes is important. Two separate studies identify AP-1 binding sites as one of the most frequent DNA regulatory elements that co-segregate with Wnt response elements (WRE). ${ }^{[1,82]}$ The functional consequence of this co-segregation is that LEF/ TCF/ $\beta$-catenin complexes and AP-1 factors co-occupy and synergize for transcriptional regulation. ${ }^{[79,83,84]}$ Synergy between Wnt and integrin-triggered AP-1 suggests that non-canonical signaling is highly sensitive to extracellular matrix connections.

Given the variety of extracellular signals that can modify Wnt signaling in colon cancer, one might presume that the level of oncogenic potential in individual patient tumors, and even within regions of a single tumor, lies along a continuum of strong to weak Wnt signaling. Indeed, if nuclear $\beta$-catenin levels are any measure of the strength of Wnt signaling, it would seem that the invasion front of a tumor, i.e., the cells with the greatest exposure to stroma and the tumor environment, should have the highest concentrations of nuclear $\beta$-catenin. This is certainly the case. ${ }^{[77,85,86]}$ These examples of synergy and cross-talk imply that signals that enhance the canonical Wnt pathway could be bonafide targets for therapy, whereas missing signals that can counter Wnt action could be re-introduced as treatments.

\section{CONSIDERATIONS FOR WNT-FOCUSED CLINICAL THERAPEUTICS OF COLON CANCER}

Given the pivotal role of Wnt signaling in the development of colon cancer and many other malignancies, it would seem an ideal target for new cancer drugs. Several cancer drugs have been approved or are in late-stage clinical trials that effectively target the EGFR, the AKT, and the Hedgehog signaling pathways. ${ }^{[87-89]}$ However, clinically useful agents to inhibit Wnt signaling pathways have, despite significant investment by several pharmaceutical and biotech companies, remained elusive. A lack of Wnt agents might reflect the difficulty in identifying 'druggable' targets in the pathway, enzymes amenable to small-molecule inhibition. But the surprising lack of new drugs might also be due to the perception that a downstream mutation in APC or CTNNB1 ( $\beta$-catenin) would make the manipulation of upstream components therapeutically ineffective. ${ }^{[90]}$ The recognition that the colon cancer phenotype can be suppressed by secreted inhibitors of Fz/LRP5/6 (DKK-1) or Wnt ligands
(SFRP) argues that 'druggable' targets upstream of APC

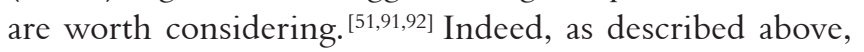
abrogation of autocrine signaling through epigenetic silencing of the inhibitory soluble Fz-related proteins (SFRPs) appears to be a naturally occurring mechanism in many types of cancer. ${ }^{[55,93-97]}$ These tumors may possess a growth advantage via blockage of natural Wnt inhibitory feedback loops. Blocking Wnt signaling by introduction of SFRP-like molecules suppresses tumor cell growth and proliferation in in vivo models in tumor cells which carry an activated form of $\beta$-catenin. ${ }^{[98]}$ The presence of methylation, which silences SFRP1 in breast cancer, is associated with an unfavorable prognosis, emphasizing the clinical significance of cell surface components as they relate to modulation of Wnt signal throughput. ${ }^{[99]}$

Many potential Wnt modulating drugs are being investigated, but there are few currently in clinical trials. ${ }^{[100-104]} \mathrm{A}$ study supported by Momotaro-Gene Inc. (NCT01197209) delivers DKK-3, an inhibitor of the Fz-LRP cell surface complex, via a viral vector in a neoadjuvant fashion for prostate cancer. No results from this phase I trial are yet available. More advanced is the use of a Novartis compound, BHQ880, for the treatment of bone disease in multiple myeloma (NCT00741377). In myeloma, decreased activity of osteoblasts contributes to the development of lytic bone lesions. ${ }^{[105]}$ Osteoblasts are inhibited by the production of DKK-1 by myeloma cells. BHQ880 is an anti-DKK-1 neutralizing antibody. Thus, for this 'cancer' indication, the approach is to block inhibition of the Wnt pathway in osteoblasts in order to prevent a cancerrelated complication.

Additional clinical research has focused on inhibition of Wnt signaling through dietary manipulations (NCT00256334, NCT00578396, and NCT01214681) as a colon cancer chemoprevention approach. These studies are based in part on the observation that certain naturally occurring compounds may inhibit Wnt signaling in vitro. ${ }^{[106,107]}$ However, while this approach may be applicable in a general sense for cancer prevention, it is nonspecific and unlikely to be clinically efficacious in the setting of frank malignancy. Another interesting compound is the pyrvinium, which potentiates casein kinase 1-alpha activity and is utilized clinically as an anthelminthic for the treatment of pinworms. ${ }^{[108,109]}$ Pyrvinium treatment of APC-defective colon cancer cells degrades Pygopus and decreases oncogenic Wnt signaling in colon cancer cells. Interestingly, increases in Pygopus1 and Pygopus 2 mRNA have been detected in villous adenomas, the relatively more aggressive precursor to colon carcinoma. ${ }^{[110]}$ Finally, a chemical genetic screen has identified XAV939, a small molecule that selectively inhibits $\beta$-catenin-mediated transcription by targeting the poly-ADP-ribosylating 
enzyme Tankyrase. Tankyrase inhibition stabilizes the Axin scaffold of the destruction complex and forces $\beta$-catenin degradation in colon cancer cells. ${ }^{[111]}$

Overall, the targeting of the Wnt pathway for cancer treatment and prevention remains in its infancy. Initial approaches have focused on inhibiting critical downstream events such as $\beta$-catenin/TCF interactions or small molecules that disrupt the interaction of $\beta$-catenin with co-activators such as CREBbinding protein (CBP).$^{[12,113]}$ Targeting upstream events via antibodies to Wnt ligands, SFRPs or SFRP-like molecules, is a more recent approach. ${ }^{[114,115]}$ Antagonizing Fz-Dvl interactions with small molecules or peptide inhibitors may also prove useful. ${ }^{[16,117]}$ Recently, inhibitors of porcupine, a membrane-bound acetyltransferase that is essential for the production of Wnt proteins and that interrupts the autocrine Wnt feedback loop, have been identified. ${ }^{[118]}$ These represent an exciting class of molecules that may preferentially target cells with activated Wnt signaling, such as tumor cells. All of these approaches primarily target canonical Wnt signaling. Nonetheless, inhibition of upstream events may also inhibit non-canonical signaling and this may not be beneficial. It may be preferable to augment, or at a minimum, not inhibit signaling induced by some Wnt ligands, such as Wnt5a. Further understanding of both canonical and non-canonical signaling pathways, other signaling pathways that cross-talk with the Wnt pathway, and factors that may modify signals despite mutationassociated activation, will be essential to guide the development of a new class of therapeutic interventions.

\section{ACKNOWLEDGMENTS}

We would like to thank Dr. Xing Dai (University of California, Irvine) and Dr. Christopher C.W. Hughes (University of California, Irvine) for helpful suggestions. M.L.W. and R.N. are supported by RO1 CA096878 and RO1 CA108697, and R.F.H. is supported by K24CA82450. Dr. Waterman and Dr. Holcombe contributed equally as senior authors for this publication

\section{REFERENCES}

I. van Amerongen R, Nusse R. Towards an integrated view of Wnt signaling in development. Development 2009;136:3205-14.

2. Waterman ML. Lymphoid enhancer factor/T cell factor expression in colorectal cancer. Cancer Metastasis Rev 2004;23:4I-52.

3. Reya T, Clevers H. Wht signalling in stem cells and cancer. Nature 2005;434:843-50.

4. MacDonald $\mathrm{BT}$, Tamai $\mathrm{K}, \mathrm{He} \mathrm{X}$. Wnt/beta-catenin signaling: components, mechanisms, and diseases. Dev Cell 2009;17:9-26.

5. Belenkaya TY, Han C, Standley HJ, Lin X, Houston DW, Heasman J, et al. Pygopus Encodes a nuclear protein essential for wingless $/ \mathrm{Wnt}$ signaling. Development 2002;129:4089-101.

6. Kramps T, Peter O, Brunner E, Nellen D, Froesch B, Chatterjee S, et al. Wnt/ wingless signaling requires $B C L 9 /$ legless-mediated recruitment of pygopus to the nuclear beta-catenin-TCF complex. Cell 2002;109:47-60.

7. Firestein R, Bass AJ, Kim SY, Dunn IF, Silver SJ, Guney I, et al. CDK8 is a colorectal cancer oncogene that regulates beta-catenin activity. Nature
2008;455:547-5।.

8. Sierra J, Yoshida T, Joazeiro CA, Jones KA. The APC tumor suppressor counteracts beta-catenin activation and $\mathrm{H} 3 \mathrm{~K} 4$ methylation at Wnt target genes. Genes Dev 2006;20:586-600.

9. Parker DS, Jemison J, Cadigan KM. Pygopus, a nuclear PHD-finger protein required for Wingless signaling in Drosophila. Development 2002;129: 2565-76.

10. Townsley FM, Thompson B, Bienz M. Pygopus residues required for its binding to Legless are critical for transcription and development. J BiolChem 2004;279:5 177-83.

II. Kohn AD, Moon RT. Wnt and calcium signaling: beta-catenin-independent pathways. Cell Calcium 2005;38:439-46.

12. Widelitz R. Wnt signaling through canonical and non-canonical pathways: recent progress. Growth Factors 2005;23:1 I I-6.

13. Mikels AJ, Nusse R. Whts as ligands: processing, secretion and reception. Oncogene 2006;25:746I-8.

14. Mikels AJ, Nusse R. Purified Wnt5a protein activates or inhibits beta-cateninTCF signaling depending on receptor context. PLoSBiol 2006;4:el I5.

15. Cha SW, Tadjuidje E, White J, Wells J, Mayhew C, Wylie C, et al. Wnt I I/5a complex formation caused by tyrosine sulfation increases canonical signaling activity. CurrBiol 2009;19:1573-80.

16. Klaus A, Birchmeier W.Wnt signalling and its impact on development and cancer. Nat Rev Cancer 2008;8:387-98.

17. van der Flier LG, Clevers $\mathrm{H}$. Stem cells, self-renewal, and differentiation in the intestinal epithelium. Annu Rev Physiol 2009;71:24I-60.

18. Korinek V, Barker N, Moerer P, van Donselaar E, Huls G, Peters PJ, et al. Depletion of epithelial stem-cell compartments in the small intestine of mice lacking Tcf-4. Nat Genet 1998; 19:379-83.

19. Lin $G, X u N, X i$ R. Paracrine Wingless signalling controls self-renewal of Drosophila intestinal stem cells. Nature 2008;455: I I 19-23.

20. Barker N, van Es JH, Kuipers J, Kujala P, van den Born M, Cozijnsen M, et al. Identification of stem cells in small intestine and colon by marker gene Lgr5. Nature 2007;449:1003-7.

21. van der Flier LG, van Gijn ME, Hatzis P, Kujala P, Haegebarth A, Stange DE, et al. Transcription factor achaetescute-like 2 controls intestinal stem cell fate. Cell 2009; 136:903-12.

22. Blache P, van de Wetering M, Duluc I, Domon C, Berta P, Freund JN, et al. SOX9 is an intestine crypt transcription factor, is regulated by the Wnt pathway, and represses the CDX2 and MUC2 genes.J Cell Biol 2004; 166:3747.

23. vanEs JH, Jay P, Gregorieff A, van Gijn ME, Jonkheer S, Hatzis P, et al. Wnt signalling induces maturation of Paneth cells in intestinal crypts. Nat Cell Biol 2005;7:38I-6.

24. Polakis P. Wnt signaling and cancer.Genes Dev 2000;14:|837-5।.

25. Brown AM. Wnt signaling in breast cancer: have we come full circle? Breast Cancer Res 2001;3:35I-5.

26. Rubinfeld B, Robbins P, El-Gamil M, Albert I, Porfiri E, Polakis P. Stabilization of beta-catenin by genetic defects in melanoma cell lines. Science 1997;275: 1790-2.

27. Korinek V, Barker N, Morin PJ, van Wichen D, de Weger R, Kinzler KW, et al. Constitutive transcriptional activation by a beta-catenin-Tcf complex in APC-/- colon carcinoma. Science 1997;275: 1784-7.

28. Morin PJ, Sparks AB, Korinek V, Barker N, Clevers H, Vogelstein B, et al. Activation of beta-catenin-Tcf signaling in colon cancer by mutations in beta-catenin or APC. Science 1997;275: 1787-90.

29. Fearon ER,Vogelstein B.A genetic model for colorectal tumorigenesis. Cell 1990;61:759-67.

30. Kinzler KW, Nilbert MC, Su LK, Vogelstein B, Bryan TM, Levy DB, et al. Identification of FAP locus genes from chromosome $5 \mathrm{q} 21$. Science 1991;253:661-5.

31. Nishisho I, Nakamura Y, Miyoshi Y, Miki Y, Ando H, Horii A, et al. Mutations of chromosome $5 \mathrm{q} 21$ genes in FAP and colorectal cancer patients. Science 1991;253:665-9.

32. Groden J, Thliveris A, Samowitz W, Carlson M, Gelbert L, Albertsen H, et al. Identification and characterization of the familial adenomatous polyposis coli gene. Cell 1991;66:589-600.

33. Okamoto M, Sato C, Kohno Y, Mori T, Iwama T,Tonomura A, et al. Molecular nature of chromosome $5 q$ loss in colorectal tumors and desmoids from patients with familial adenomatous polyposis. Hum Genet 1990;85:595-9.

34. Rubinfeld B, Souza B, Albert I, Müller O, Chamberlain SH, Masiarz FR, 
et al. Association of the APC gene product with beta-catenin. Science 1993;262:173|-4.

35. Miyaki M, Konishi M, Kikuchi-Yanoshita R, Enomoto M, Igari T,Tanaka K, et al. Characteristics of somatic mutation of the adenomatous polyposis coli gene in colorectal tumors. Cancer Res 1994;54:30 I I-20.

36. Polakis P. The oncogenic activation of beta-catenin. Curr Opin Genet Dev 1999;9:I5-2I.

37. LiuW,Dong X, Mai M, Seelan RS, Taniguchi K, Krishnadath KK, et al. Mutations in AXIN2 cause colorectal cancer with defective mismatch repair by activating beta-catenin/TCF signalling. Nat Genet 2000;26:146-7.

38. Merritt AJ, Gould KA, Dove WF. Polyclonal structure of intestinal adenomas in ApcMin/+ mice with concomitant loss of Apc+ from all tumor lineages. Proc Natl Acad Sci USA 1997;94:|3927-31.

39. Phelps RA, Chidester S, Dehghanizadeh S, Phelps J, Sandoval IT, Rai K, et al. A two-step model for colon adenoma initiation and progression caused by APC loss. Cell 2009; 137:623-34.

40. Arce L, Yokoyama NN, Waterman ML. Diversity of LEF/TCF action in development and disease. Oncogene 2006;25:7492-504.

4I. Atcha FA, Syed A, Wu B, Hoverter NP, Yokoyama NN,Ting JH, et al. A unique DNA binding domain converts T-cell factors into strong Wnt effectors. Mol Cell Biol 2007;27:8352-63.

42. Chang MV, Chang JL, Gangopadhyay A, Shearer A, Cadigan KM. Activation of wingless targets requires bipartite recognition of DNA by TCF. CurrBiol 2008; |8: |877-8|.

43. Hovanes K, LiTW, Munguia JE,Truong T, Milovanovic T, Lawrence Marsh J, et al. Beta-catenin-sensitive isoforms of lymphoid enhancer factor-I are selectively expressed in colon cancer. Nat Genet 200I;28:53-7.

44. van deWetering $M$, Oosterwegel $M$, Dooijes $D$, Clevers $H$. Identification and cloning of TCF-I, a T lymphocyte-specific transcription factor containing a sequence-specific HMG box. EMBO J 1991;10:123-32.

45. Korinek V, Barker N,Willert K, Molenaar M, Roose J,Wagenaar G, et al. Two members of the Tcf family implicated in Wnt/beta-catenin signaling during embryogenesis in the mouse. Mol Cell Biol 1998; 18:1248-56.

46. Roose J, Huls G, van Beest M, Moerer P, van der Horn K, Goldschmeding $\mathrm{R}$, et al. Synergy between tumor suppressor APC and the beta-catenin-Tcf4 target Tcfl. Science 1999;285:1923-6.

47. Najdi R, Syed A,Arce L,Theisen H,Ting JH,Atcha F,et al. AWnt kinase network alters nuclear localization of TCF-I in colon cancer. Oncogene 2009;28: 4I33-46.

48. Li TW, Ting JH, Yokoyama NN, Bernstein A, van de Wetering M, Waterman ML.Wnt activation and alternative promoter repression of LEFI in colon cancer. Mol Cell Biol 2006;26:5284-99.

49. Yokoyama NN, Pate KT,Sprowl S,Waterman ML. A role for YYI in repression of dominant negative LEF-I expression in colon cancer. Nucleic Acids Res 2010;38:6375-88.

50. Kaiser S, ParkYK, Franklin JL, Halberg RB,Yu M, Jessen WJ, et al. Transcriptional recapitulation and subversion of embryonic colon development by mouse colon tumor models and human colon cancer. Genome Biol 2007;8:RI3I.

5I. Bafico A, Liu G, Goldin L, Harris V, Aaronson SA. An autocrine mechanism for constitutive Wnt pathway activation in human cancer cells. Cancer Cell 2004:6:497-506.

52. Holcombe RF, Marsh JL, Waterman ML, Lin F, Milovanovic T, Truong T. Expression of Wnt ligands and Frizzled receptors in colonic mucosa and in colon carcinoma. Mol Pathol 2002;55:220-6.

53. Smith K, Bui TD, Poulsom R, Kaklamanis L, Williams G, Harris AL. UPregulation of macrophage $\mathrm{Wnt}$ gene expression in adenoma-carcinoma progression of human colorectal cancer. Br J Cancer 1999;81:496-502.

54. Park JK, Song JH, He TC, Nam SW, Lee JY, ParkWS. Overexpression of Wnt-2 in colorectal cancers. Neoplasma 2009;56:I I 9-23.

55. Suzuki H, Watkins DN, Jair KW, Schuebel KE, Markowitz SD, Chen WD, et al. Epigenetic inactivation of SFRP genes allows constitutive Wnt signaling in colorectal cancer. Nat Genet 2004;36:4I 7-22.

56. You XJ, Bryant PJ, Jurnak F, Holcombe RF. Expression of Wnt pathway components frizzled and disheveled in colon cancer arising in patients with inflammatory bowel disease. Oncol Rep 2007; 18:69|-4.

57. González-Sancho JM, Aguilera O, García JM, Pendás-Franco N, Peña C, Cal $\mathrm{S}$, et al. The Wnt antagonist DICKKOPF-I gene is a downstream target of beta-catenin/TCF and is downregulated in human colon cancer. Oncogene 2005;24:1098-103.

58. Caldwell GM, Jones C, Gensberg K, Jan S, Hardy RG, Byrd P, et al. The Wnt antagonist sFRPI in colorectal tumorigenesis. Cancer Res 2004;64:883-8.
59. Aguilera O, Fraga MF, Ballestar E, Paz MF, Herranz M, Espada J, et al. Epigenetic inactivation of the Wnt antagonist DICKKOPF-I (DKK-I) gene in human colorectal cancer. Oncogene 2006;25:4I I6-2I.

60. Dejmek J, Dejmek A, Säfholm A, Sjölander A, Andersson T. Wnt-5a protein expression in primary dukes $B$ colon cancers identifies a subgroup of patients with good prognosis. Cancer Res 2005;65:9|42-6.

6I. Lee JM, Kim IS, Kim H, Lee JS, Kim K, Yim HY, et al. ROR alpha attenuates Wnt/beta-catenin signaling by PKC alpha-dependent phosphorylation in colon cancer. Mol Cell. 2010;37:183-95.

62. MacLeod RJ, Hayes M, Pacheco I. Wnt5a secretion stimulated by the extracellular calcium-sensing receptor inhibits defectiveWnt signaling in colon cancer cells. Am J Physiol Gastrointest Liver Physiol 2007;293:G403-I I.

63. Ying J, Li H, Yu J, Ng KM, Poon FF, Wong SC, et al. Wnt5A exhibits tumorsuppressive activity through antagonizing the Wnt/beta-catenin signaling, and is frequently methylated in colorectal cancer. Clin Cancer Res 2008; |4:55-6I .

64. Ishitani T, Ninomiya-Tsuji J, Nagai S, Nishita M, Meneghini M, Barker N, et al. The TAKI-NLK-MAPK-related pathway antagonizes signalling between beta-catenin and transcription factor TCF. Nature 1999;399:798-802.

65. Ishitani T, Kishida S, Hyodo-Miura J, Ueno N, Yasuda J, Waterman M, et al. The TAKI-NLK mitogen-activated protein kinase cascade functions in the Wnt-5a/Ca(2+) pathway to antagonize Wnt/beta-catenin signaling. Mol Cell Biol 2003;23:131-9.

66. Galon J, Costes A, Sanchez-Cabo F, Kirilovsky A, Mlecnik B, Lagorce-Pagès $C$, et al. Type, density, and location of immune cells within human colorectal tumors predict clinical outcome. Science 2006;313:1960-4.

67. Zlobec I, Minoo P, Baumhoer D, Baker K, Terracciano L, Jass JR, et al. Multimarker phenotype predicts adverse survival in patients with lymph node-negative colorectal cancer. Cancer 2008; I I2:495-502.

68. Lugli A, Karamitopoulou E, Panayiotides I, Karakitsos P, Rallis G, Peros G, et al. CD8+ lymphocytes/tumour-budding index: an independent prognostic factor representing a 'pro-/anti-tumour' approach to tumour host interaction in colorectal cancer. Br J Cancer 2009; 101:1382-92.

69. Camus M, Tosolini M, Mlecnik B, Pagès F, Kirilovsky A, Berger A, et al. Coordination of intratumoral immune reaction and human colorectal cancer recurrence. Cancer Res 2009;69:2685-93.

70. McDonald SL, Silver A.The opposing roles of $\mathrm{Wnt}-5 \mathrm{a}$ in cancer. $\mathrm{Br} \mathrm{J}$ Cancer 2009; 101:209-14.

7I. Bos JL, Fearon ER, Hamilton SR, Verlaan-de Vries M, van Boom JH, van der Eb AJ, et al. Prevalence of ras gene mutations in human colorectal cancers. Nature 1987;327:293-7.

72. Forrester K,Almoguera C, Han K, GrizzleWE, Perucho M. Detection of high incidence of K-ras oncogenes during human colon tumorigenesis. Nature 1987;327:298-303

73. Wu X, Tu X, Joeng KS, Hilton MJ, Williams DA, Long F. Racl activation controls nuclear localization of beta-catenin during canonical Wnt signaling. Cell 2008; 133:340-53

74. Moran AE, Hunt DH, Javid SH, Redston M, Carothers AM, Bertagnolli MM. Apc deficiency is associated with increased Egfr activity in the intestinal enterocytes and adenomas of C57BL/6J-Min/+ mice. J BiolChem 2004;279:4326I-72

75. HuT, Li C. Convergence between Wnt- $\beta$-catenin and EGFR signaling in cancer. Mol Cancer 2010;9:236

76. Allegra CJ, Jessup JM, Somerfield MR, Hamilton SR, Hammond EH, Hayes DF, et al. American Society of Clinical Oncology provisional clinical opinion: testing for KRAS gene mutations in patients with metastatic colorectal carcinoma to predict response to anti-epidermal growth factor receptor monoclonal antibody therapy. J ClinOncol 2009;27:209 I-6.

77. Vermeulen L, De Sousa E Melo F, van der Heijden M, Cameron K, de Jong JH, Borovski T, et al. Wnt activity defines colon cancer stem cells and is regulated by the microenvironment. Nat Cell Biol 2010;12:468-76.

78. Corso S, Migliore C, Ghiso E, De Rosa G, Comoglio PM, Giordano S. Silencing the MET oncogene leads to regression of experimental tumors and metastases. Oncogene 2008;27:684-93.

79. Crampton SP, Wu B, Park EJ, Kim JH, Solomon C, Waterman ML, et al. Integration of the beta-catenin-dependent Wnt pathway with integrin signaling through the adaptor molecule Grb2. PLoS One 2009;4:e784I.

80. Novak A, Hsu SC, Leung-Hagesteijn C, Radeva G, Papkoff J, Montesano R, et al. Cell adhesion and the integrin-linked kinase regulate the LEF-I and beta-catenin signaling pathways. Proc Natl Acad Sci USA 1998;95:4374-9.

81. Hatzis P, van der Flier LG, van Driel MA, Guryev V, Nielsen F, Denissov $\mathrm{S}$, et al. Genome-wide pattern of TCF7L2/TCF4 chromatin occupancy in 
colorectal cancer cells. Mol Cell Biol 2008;28:2732-44.

82. Bottomly D, Kyler SL, McWeeney SK, Yochum GS. Identification of \{beta\}catenin binding regions in colon cancer cells using ChIP-Seq. Nucleic Acids Res 2010;38:5735-45.

83. Nateri AS, Spencer-Dene B, Behrens A. Interaction of phosphorylated c-Jun with TCF4 regulates intestinal cancer development. Nature 2005;437: $28 \mathrm{I}-5$.

84. Toualbi K, Güller MC, Mauriz JL, Labalette C, Buendia MA, Mauviel A, et al. Physical and functional cooperation between AP-I and beta-catenin for the regulation of TCF-dependent genes. Oncogene 2007;26:3492-502.

85. Kirchner T, Brabletz T. Patterning and nuclear beta-catenin expression in the colonic adenoma-carcinoma sequence. Analogies with embryonic gastrulation. Am J Pathol 2000;157:III3-2I.

86. Brabletz T, Jung A, Kirchner T. Beta-catenin and the morphogenesis of colorectal cancer. Virchows Arch 2002;44 I: I- I I.

87. Vivanco I, Mellinghoff IK. Epidermal growth factor receptor inhibitors in oncology. CurrOpinOncol 2010;22:573-8.

88. Ou SH, Bazhenova L, Camidge DR, Solomon BJ, Herman J, Kain T, et al. Rapid and dramatic radiographic and clinical response to an ALK inhibitor (crizotinib, PF02341066) in an ALK translocation-positive patient with nonsmall cell lung cancer. J Thorac Oncol 2010;5:2044-6.

89. Garber K. Hedgehog drugs begin to show results. J Natl Cancer Inst 2008; 100:692-7.

90. Garber K. Drugging theWnt pathway: problems and progress. J Natl Cancer Inst 2009; 101:548-50.

91. Schlange T, Matsuda Y, Lienhard S, Huber A, Hynes NE. AutocrineWnt signaling contributes to breast cancer cell proliferation via the canonicalWnt pathway and EGFR transactivation. Breast Cancer Res 2007;9:R63.

92. Taketo MM. Shutting down Wnt signal-activated cancer. Nat Genet 2004:36:320-2.

93. Suzuki H, Toyota M, Carraway H, Gabrielson E, Ohmura T, Fujikane T, et al. Frequent epigenetic inactivation of Wnt antagonist genes in breast cancer. Br J Cancer 2008;98: I |47-56.

94. Bu XM, Zhao CH, Zhang N, Gao F, Lin S, Dai XW. Hypermethylation and aberrant expression of secreted frizzled-related protein genes in pancreatic cancer. World J Gastroenterol 2008; | 4:342I-4.

95. Takagi H, Sasaki S, Suzuki H, Toyota M, Maruyama R, Nojima M, et al. Frequent epigenetic inactivation of SFRP genes in hepatocellular carcinoma. J Gastroenterol 2008;43:378-89.

96. Hirata H, Hinoda Y, Ueno K, Majid S, Saini S, Dahiya R. Role of secreted frizzled-related protein 3 in human renal cell carcinoma. Cancer Res 2010;70: 1896-905.

97. Nojima M, Suzuki H, Toyota M, Watanabe Y, Maruyama R, Sasaki S, et al. Frequent epigenetic inactivation of SFRP genes and constitutive activation of Wnt signaling in gastric cancer. Oncogene 2007;26:4699-7।3.

98. Lavergne E, Hendaoui I, Coulouarn C, Ribault C, Leseur J, Eliat PA, et al. In vivo blocking Wnt signaling by SFRP-like molecules inhibits cell proliferation and tumor growth in cells carrying active beta-catenin. Oncogene 2010;30: 423-33.

99. Veeck J, Niederacher D, An H, Klopocki E,Wiesmann F, Betz B, et al. Aberrant methylation of the Wnt antagonist SFRPI in breast cancer is associated with unfavourable prognosis. Oncogene 2006;25:3479-88. 100.

100. Barker N, Clevers H. Mining the Wnt pathway for cancer therapeutics. Nat Rev Drug Discov 2006;5:997-1014.
I0I. Chen W, Chen M, Barak LS. Development of small molecules targeting the Wnt pathway for the treatment of colon cancer:a high-throughput screening approach. Am J Physiol Gastrointest Liver Physiol 2010;299:G293-300.

102. CamilliTC,Weeraratna AT. Striking the target in Wnt-y conditions: intervening in Wnt signaling during cancer progression. BiochemPharmacol 2010;80: 702-II.

103. Hood JG, HuY,jiangY,Pedraza M, Situ E, Sunil KC. Discovery of small molecule Wnt pathway modulators. In: editor name missing Proc Keystone Conference: New Paradigms in Cancer Therapeutics; 2010.

104. Curtin JC. Drug discovery approaches to targetWnt signaling in cancer stem cells. Oncotarget 20 I0; 1:563-6.

105. Fulciniti M, Tassone P, Hideshima T, Vallet S, Nanjappa P, Ettenberg SA, et al. Anti-DKKI mAb (BHQ880) as a potential therapeutic agent for multiple myeloma. Blood 2009; I 14:37।-9.

106. Hope C, Planutis K, Planutiene M, Moyer MP, Johal KS, Woo J, et al. Low concentrations of resveratrol inhibit Wnt signal throughput in colonderived cells: implications for colon cancer prevention. Mol Nutr Food Res 2008;52:S52-61.

107. Nguyen AV, Martinez M, Stamos MJ, Moyer MP, Planutis K, Hope C, et al. Results of a phase I pilot clinical trial examining the effect of plant-derived resveratrol and grape powder on Wnt pathway target gene expression in colonic mucosa and colon cancer. Cancer Manag Res 2009; I:25-37.

108. Thorne CA, Hanson AJ, Schneider J, Tahinci E, Orton D, Cselenyi CS, et al. Small-molecule inhibition of Wnt signaling through activation of casein kinase I $\alpha$. Nat Chem Biol 2010;6:829-36.

109. Turner JA, Johnson PE, Jr:: Pyrviniumpamoate in the treatment of pinworm infection (enterobiasis) in the home. J Pediatr 1962;60:243-5I.

1 10. Nguyen AV, Albers CG, Holcombe RF. Differentiation of tubular and villous adenomas based on Wnt pathway-related gene expression profiles. Int J Mol Med 2010;26:121-5.

III. Huang SM, Mishina YM, Liu S, Cheung A, Stegmeier F, Michaud GA, et al. Tankyrase inhibition stabilizes axin and antagonizes Wnt signalling. Nature 2009;461:614-20.

112. Lepourcelet M, Chen YN, France DS, Wang H, Crews P, Petersen F, et al. Smallmolecule antagonists of the oncogenic Tcf/beta-catenin protein complex. Cancer Cell 2004:5:91-102.

113. Emami KH, Nguyen C, Ma H, Kim DH, Jeong KW, Eguchi M, et al. A small molecule inhibitor of beta-catenin/CREB-binding protein transcription [corrected]. Proc Natl Acad Sci USA 2004;101:12682-7.

I 14. He B, Reguart N, You L, Mazieres J, Xu Z, Lee AY, et al. Blockade of Wnt-I signaling induces apoptosis in human colorectal cancer cells containing downstream mutations. Oncogene 2005;24:3054-8.

II5. DeAlmeida VI, Miao L, Ernst JA, Koeppen H, Polakis P, Rubinfeld B. In vivo the soluble Wnt receptor Frizzled 8CRD-hFc inhibits the growth of teratocarcinomas. Cancer Res 2007;67:537I-9.

1 16. Shan J, Shi DL, Wang J, Zheng J. Identification of a specific inhibitor of the dishevelled PDZ domain. Biochemistry 2005;44:15495-503.

1 17. Zhang Y, Appleton BA, Wiesmann C, Lau T, Costa M, Hannoush RN, et al. Inhibition of Wnt signaling by Dishevelled PDZ peptides. Nat Chem Biol 2009;5:217-9.

I 18. Chen B, Dodge ME, TangW, Lu J, Ma Z, Fan CW, et al. Small molecule-mediated disruption of Wnt-dependent signaling in tissue regeneration and cancer. Nat Chem Biol 2009;5:100-7.

\section{AUTHOR'S PROFILE}

Dr. Rani Najdi, Department of Microbiology and Molecular Genetics, University of California, Irvine.

Dr. Marian L Waterman, Department of Microbiology and Molecular Genetics, University of California, Irvine

Dr. Randall F Holcombe, Tisch Cancer Institute, Mt. Sinai School of Medicine, New York, NY

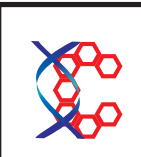

Journal of Carcinogenesis is published for Carcinogenesis Press by Medknow Publications and Media Pvt. Ltd.

Manuscripts submitted to the journal are peer reviewed and published immediately upon acceptance, cited in PubMed and archived on PubMed Central. Your research papers will be available free of charge to the entire biomedical community. Submit your next manuscript to Journal of Carcinogenesis. www.journalonweb.com/jcar/ 